\title{
Emergency Intervention Need for Community Dental Services (Pathfinder Survey in North Mamuju Regency, West Sulawesi, Indonesia)
}

\author{
Burhanuddin Daeng Pasiga and Arifurrahman Burhanuddin
}

\section{ABSTRACT}

\begin{abstract}
Background: Oral health is considered an important component of public health, but there are still many people who are less concerned with oral and dental health. Objective: to describe emergency dental care interventions for communities based on age groups in North Mamuju.West of Sulawesi, Indonesia.
\end{abstract}

\begin{abstract}
Materials, and Methods: The age categories in the survey were three age groups: children (6-12 years old), young (12-17 years old) and adults (1860 years old). Analytical observational research with Cross-sectional design, which is a survey of oral pathfinder, determined by simply taking, they are Sarjo and Bambaira Districts.
\end{abstract}

Results: The sample of 935 men with male sex was $39.7 \%$ and women $63.3 \%$. The percentage of distribution of dental care needs is $97.4 \%$. Emergency care needed is preventive care / routine care needed as much as $\mathbf{1 3 . 5 \%}$, rapid care needs as much as $\mathbf{6 5 . 8 \%}$, urgent care needs due to pain, and dental infections as much as $\mathbf{1 7 . 2 \%}$.

Conclusion: The need for emergency and immediate dental care in the community is still quite high.

Keywords: Dental Health services, Emergency, Intervention.
Published Online: August 08, 2021

ISSN: $2684-4443$

DOI: $10.24018 /$ ejdent.2021.2.4.81

Burhanuddin Daeng Pasiga*

Faculty of Dentistry, Hasanuddin University, Makassar, Indonesia. Faculty of Dentistry, Prof Dr Moestopo (Beragama) University, Jakarta, Indonesia.

(e-mail: bpasiga @unhas.ac.id) Arifurrahman Burhanuddin

Faculty of Dentistry, Prof Dr Moestopo (Beragama) University, Jakarta, Indonesia.

(e-mail:

arifurrahmanburhanuddin ${ }^{@}$ yahoo.co.id)

*Corresponding Author

\section{INTRODUCTION}

Oral health of Indonesian people is still a matter that needs serious attention from medical personnel, both doctors and dental nurses, the proportion of people who have problems, and their mouths by $57.6 \%$ and the most for the age of $45-64$ years of age of $62.1 \%$, while those receiving treatment only $10.2 \%$. Also, the prevalence of caries is as much as $88.8 \%$ [1]. Teeth and mouth disease that affects many people in Indonesia was a disease of the tissue supporting the teeth and dental caries, the source of both these diseases due to the neglect of oral hygiene so there was an accumulation of plaque. Dental and oral health care is one of the most important components of general health-related to the branch of medicine related to the prevention, diagnosis, and treatment of all diseases related to the oral cavity and teeth. [2] Oral health problems is still considered trivial for most people. The teeth and the mouth are the gateway entrance of germs and bacteria that can damage the health of other organs. Oral health is considered an important component of public health, and oral disease is one of the noncommunicable diseases that can be prevented and can result in the quality of life of a person [3]-[5]. The results of the Health Survey study of 10 groups of people who complained about most diseases, gum disease ranked first [1]. Dental services are one of the most important components of general health, and they have a direct impact on it [2], [3]. Factors that influence the low level of people who do dental care are socioeconomic factors, educational factors, geographic location factors, awareness factors of the importance of caring for teeth and mouth, consider dental health harmless [6]-[9]. In some countries access to public oral health promotion programs focused on children and adolescents by encouraging the supervision of toothbrushes, and the use of fluoride, has been carried out by the government through school health activities through mass supervision of brushing related to various methods of use of fluoride which includes fluoride gel, fluoride mouthwash, and varnish fluoride, especially in schools, attention is also directed to prevention and dental care for preschool-age to children, especially for children at the risk of caries [10], [11]. In America, 43\% of rural residents do not have regular dental care, resulting in poor dental health - a higher prevalence of complete tooth loss [12]. In addition to barriers to accessing oral health services, rural residents may also experience differences in the type of dental services received after they access the treatment, such as more dental extractions and less likely to undergo dental prophylaxis, which can be an indicator of the quality of care [1], [6]. All dental problems can be avoided by everyone when knowing how to prevention and proper care must be done. Article 47 of Law No. 36 of 2009 on Health, said health efforts are organized in the form of activity with 
the approach of promotive, preventive, curative, and rehabilitative services are conducted in an integrated, comprehensive, and sustainable. This is consistent with those contained in the council of medicine in 2015 about the standard of competence dentist Indonesia are applying the principle of service dental and oral health which includes measures promotive, preventive, curative, rehabilitative and understand how the treatment of patients with abnormal/systemic disease manifesting in the cavity mouth and be able to make a referral to another specialist fields associated with the disease/disorder patients. In some countries, including private dental practitioners, Indonesia dominates, and third-party payments are based on private insurance or fees paid by employers. While in Eastern Europe and Central Asia, oral health services are based on a mix of public and private systems [13]. In Indonesia, the utilization of services shows the average percentage of visits for dental care is $38.3 \%$. Choosing dental care in private dental practice was $53.9 \%$, choosing services at the Community Health Center (PUSKESMAS) 30\%, and hospitals 16.11\% [6]. North Mamuju capital Pasangkayu, North Mamuju is the result of the expansion of Mamuju Regency is located 719 kilometers from the provincial capital of South Sulawesi. North Mamuju regency is divided into 12 districts and 61 . The total population by 2015 in North Mamuju regency as many as 152505 people, made up 79249 males and 73256 inhabitants. Based on the health profile of North Mamuju 2018, states the medical personnel dentists in North Mamuju regency there are only 6 people which means not ideal, based on data and health information Indonesia in 2013 the ideal number of dentists in the community in the area is 1: 9000 . This indicates that the comparison of oral health problems that occur with the dental treatment received is still not comparable, so based on the above explanation the researchers want to survey emergency interventions dental care in North Mamuju regency.

\section{MATERIAL AND METHOD}

This is an analytical observational study with cross-study design, determined by taking only rural areas in Sarjo and Bambaira Districts with a sample of 935 people. The level of emergency intervention of dental treatment is carried out by determining the appropriate treatment plan after an oral health examination is recorded where the sample is divided by age group. The data in the status card on emergency dental care intervention consists of five points: $0=$ no need for the treatment, 1 = preventive or routine care required, $2=$ prompt treatment including necessary tartar cleaning, $3=$ immediate (urgent) care required due to pain or dental infection and/or oral origin, $4=$ referred for comprehensive evaluation or medical/dental care (systemic condition) [14].

\section{RESULT}

A survey has been conducted on descriptive dental care needs by age groups in the North Mamuju Regency area. The survey was conducted in Sarjo Bambaira subdistrict and subdistrict. Respondents based on all age groups of 6-60 years (children, young people, and adults) were as many as

\section{7 people.}

Table I, showing the distribution of respondents by 935 people. This shows that the number of women in this survey is more than men, there are 564 women $(60.3 \%)$ and 371 people $(39.7 \%)$. The number of children (6-12 years old) was $42.7 \%$ more than the number of respondents of adolescent and adult age groups.

TABLE I: DistRIBUTION OF SURVEY RESPONDENTS BY GENDER AND AGE CATEGORIES IN NORTH MAMUJU

\begin{tabular}{lcc}
\multicolumn{2}{c}{ CATEGORIES IN NORTH MAMUJU } \\
\hline Gender & (n) & Percentage (\%) \\
Man & 371 & $39,7 \%$ \\
Woman & 564 & $60,3 \%$ \\
Total & $\mathbf{9 3 5}$ & $\mathbf{1 0 0 . 0 \%}$ \\
Age Group & & \\
Child (6-12 years) & 399 & $42,7 \%$ \\
Young (13-16 years) & 286 & $30.6 \%$ \\
Adult (17-60 years) & 250 & $26,7 \%$ \\
Total & $\mathbf{9 3 5}$ & $\mathbf{1 0 0 . 0 \%}$ \\
\hline
\end{tabular}

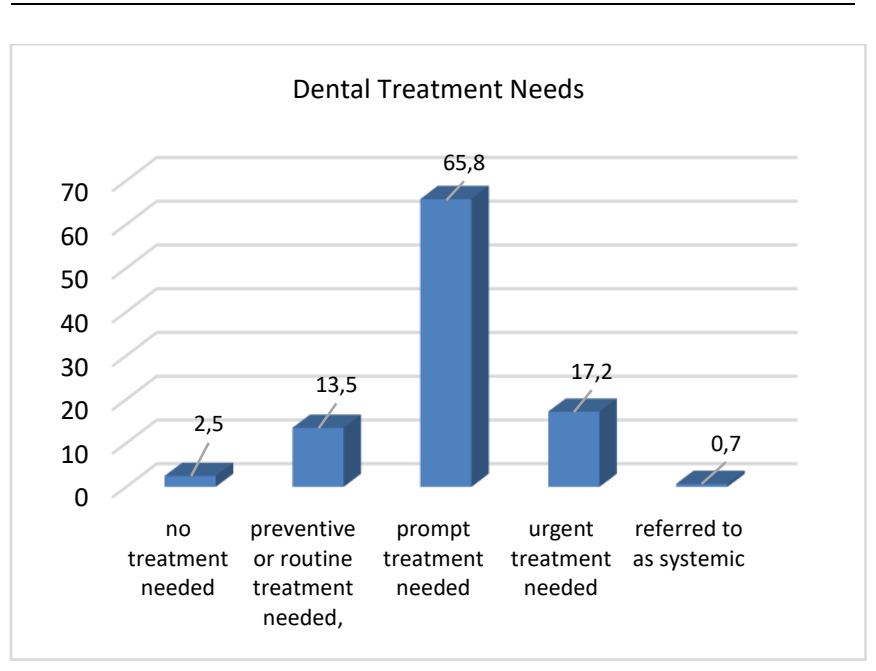

Fig. 1. Distribution of the percentage of dental treatment needs in North Mamuju.

Fig. 1 shows the distribution of interventions of survey respondents in the North Mamuju Regency area. It appears that the number of respondents who do not have treatment is needed by $24(2.5 \%) .127$ preventive/routine care $(13.5 \%)$, $616(65.8 \%)$, urgent treatment due to pain and dental infections $161(17.2 \%)$, were referred for comprehensive dental/medical evaluation or treatment (systemic conditions) $7(0.7 \%)$.

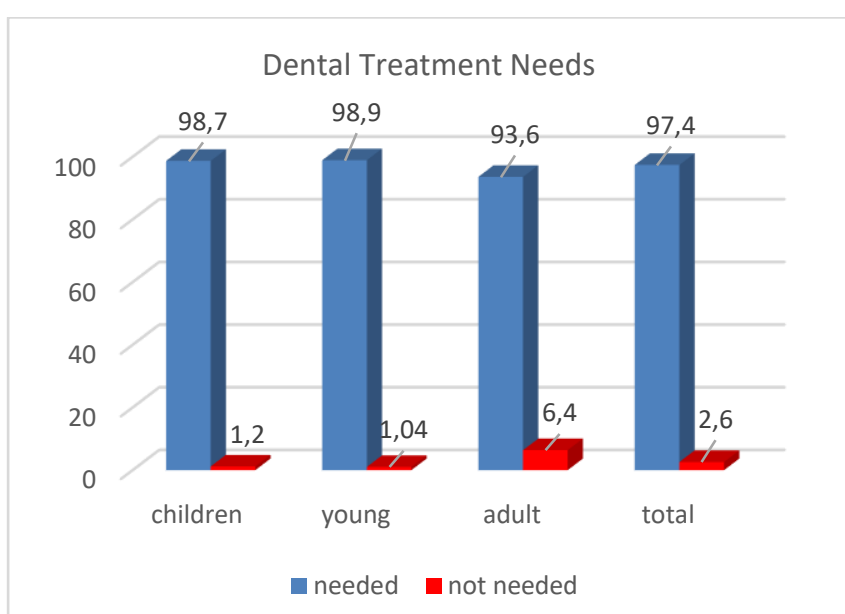

Fig. 2. Distribution of the percentage of dental treatment needs based on age groups in North Mamuju. 
Fig. 2 shows that the percentage distribution of dental treatment needs to be based on age is as high as much as $97.4 \%$. Dental care needs as much as $98.7 \%$ in children, young, as much as $98.9 \%$, and adults as much as $93.6 \%$.

Fig. 3 shows the distribution of the survey respondents' dental care needs by age group in the North Mamuju regency. Preventive / routine care needed as many as 79 children (19.7\%), 24 young (8.3\%), 24 adults (9.6\%). Prompt treatment needed as many as 242 children $(60.6 \%), 208$ young $(72.7 \%), 166$ adults $(66.4 \%)$. Needed urgent care because of pain/pain and tooth infection as many as 73 children - children (18.2\%), 51 young (17.8\%), 37 adults (14.8\%), referred for a comprehensive evaluation or treatment of dental/medical (systemic conditions) 7 (2.8\%) people present only in adult.

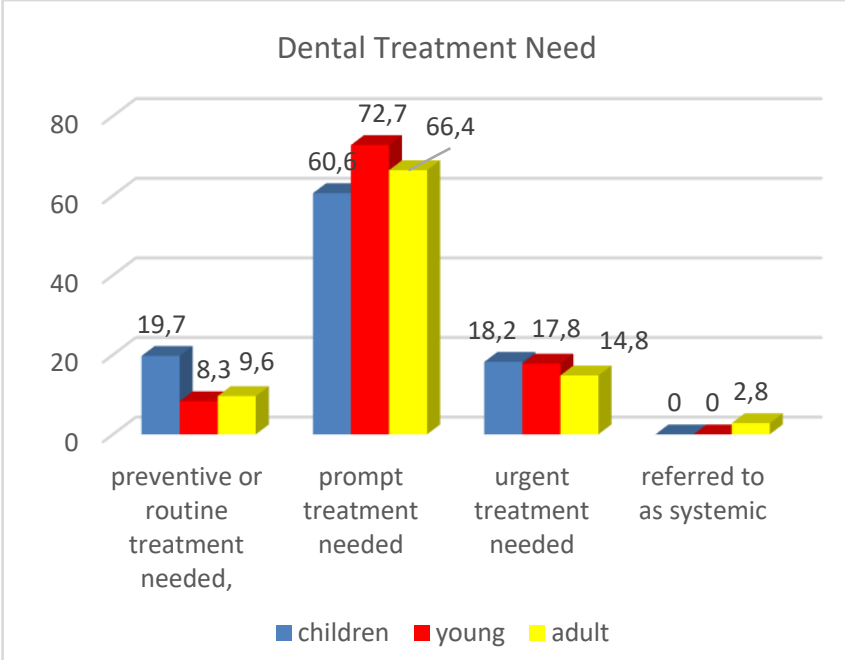

Fig. 3. Percentage distribution of dental care needs by age group in North Mamuju.

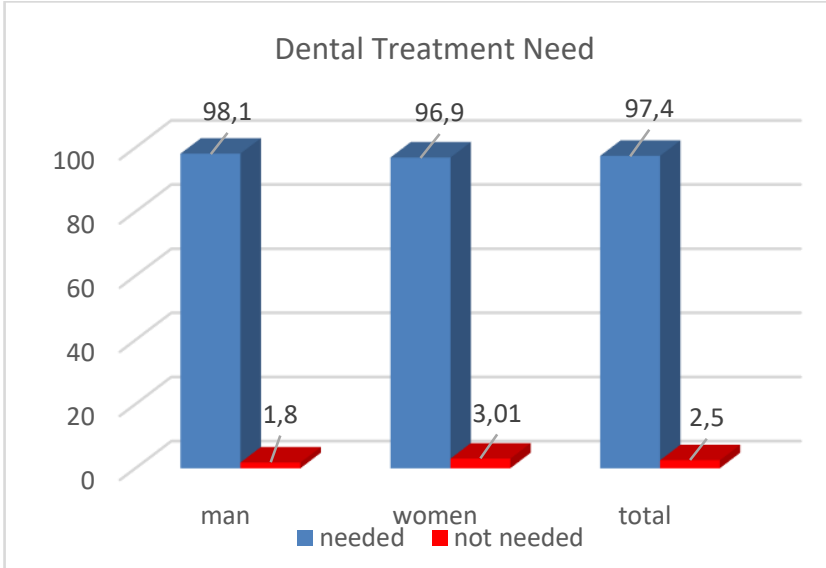

Fig. 4. Distribution of the percentage of dental treatment needs based on gender in North Mamuju.

Fig. 4 shows that the distribution of dental treatment needs to be based on gender is as high as much as $97.4 \%$. Dental care needs in men as much as $98.1 \%$, women as much as $96.9 \%$.

Fig. 5 shows the distribution of the survey respondent's dental care needs to be based on gender in North Mamuju regency. Seen that Preventive / routine care needed were 51 men $(13.7 \%), 76$ women $(13.4 \%)$, prompt treatment needed as many as 248 men $(66.8 \%), 368$ women $(65.2 \%)$, needed urgent care because of pain/pain and tooth infection as much as 61 men (16.4\%), 100 women (17.7\%), was referred for a comprehensive evaluation or treatment of dental/medical (systemic conditions) as much as 4 men (1.07\%), 3 women $(0.5 \%)$

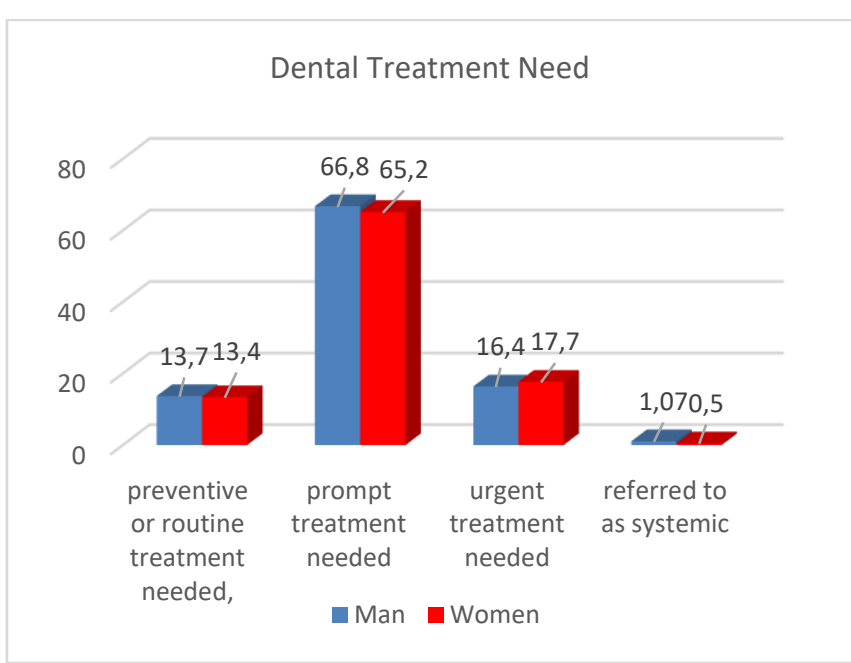

Fig. 5. Distribution of the percentage of dental treatment needs based on gender in North Mamuju.

\section{DISCUSSION}

Healthy according to the World Health Organization (WHO) is a situation perfect physical, mental, social, and even free of illness or disability. Oral health is the starting gate for overall body health $[15,16]$. Oral health problems known as an important factor that negatively impacts daily life and affects the quality of life because it can predispose a person to enjoy life and socialize even can damage the health of the body. The World Health Organization (WHO) states that oral disease can cause pain, suffering, psychological problems, and impaired social interaction [4], [14], [17].

Dentists in Indonesia to increase the degree of public health shall act as motivators, educators, and health care providers (promotive, preventive, curative, and rehabilitative). By providing health care, dentists shall be efficient, effective, and quality according to the needs, and requests of patients [1], [6]. Dental and oral care such as tooth extraction, filling, and root canal therapy is something that is relatively expensive compared to the efforts of preventive oral health. Urgency intervention and restorative, such as filling and root canal therapy in essence can stop the disease, but it cannot return the teeth and gum tissue naturally. The results were obtained that the emergency care needs as $17.7 \%$, this result is higher than the research by Huang, Jing Yang, et al. as much as $(5.68 \%)$ had repeated emergency dental visits within 1 year [18].

In this study it is known that dental care needs are very high at $97.4 \%$ and the most needed care is the right care needed by $65.8 \%$. This is in accordance with several studies conducted in several regions in Indonesia that showed that dental treatment needs are still very high at $99.6 \%$ and the most needed treatment is filling teeth, as is found in some countries such as China [19], [20]. Based on this survey, it is known that very high dental care needs are the right care needed by $65.8 \%$. This happens because of the lack of public awareness to carry out routine dental care, which can be influenced as 
well as socioeconomic status [13], [21], [16], [22]. In the survey conducted in rural areas, it is known that dental treatment needs are very high at $97.4 \%$ and the treatments that were most needed are the proper care required for $65.8 \%$. The result is no different from the report from the Ministry of Health of the Republic of Indonesia, where many Indonesians still need dental care as much as $95.5 \%$ [1]. In this survey to determine the level of dental care needs are still very high at $97.4 \%$, this indicates that the dental health status of the people of North Mamuju is still very bad. This is in line with research conducted Crouch $\mathrm{S}$ et al. on the status of oral health in adults in rural areas of Meru Kenya showed that caries high levels of as much as $99 \%$, gingival inflammation as much as $90 \%$, and mouth disease was found as much as $81 \%$ [23]. Poor dental health status in society is caused by the limited actions to perform dental treatments shows there is a very high need for dental treatments and oral and implementation of effective prevention strategies for these communities [24].

\section{CONCLUSION}

Based on the results of the survey shows that the need for dental care needs in the community is very high, especially the need for emergency care in the form of prompt treatment needed either children group, adolescent group, or adult group.

\section{ACKNOWLEDGMENT}

Thanks to the Government of District Pasang Kayu North Mamuju Regency who has given permission and has participated in this survey, also especially students of the Faculty of Dentistry Hasanuddin University who participated and helped the implementation of this survey.

\section{REFERENCES}

[1] B. P. d. P. K. K. K. R. Indonesia, "Riset Kesehatan Dasar Nasional," Kementerian Kesehatan RI, Jakarta, 2018.

[2] Şahin, Bayram İlgün, Gülnur, "Assessment of the efficiency of dental services in Turkey," Health Policy and Technology, vol. 7, no. 2, pp. 173-181, 2018. doi: 10.1016/j.hlpt.2018.03.001.

[3] Masood, Mohd Newton, Tim Bakri, Noor Nazahiah Khalid, Taimur Masood, Yaghma, "The relationship between oral health and oral health related quality of life among elderly people in United Kingdom," Journal of Dentistry, vol. 56, pp. 78-83, 2017. http://dx.doi.org/10.1016/j.jdent.2016.11.002

[4] M. Younsi, "Health-Related Quality-of-Life Measures : Evidence from Tunisian Population Using the SF-12 Health Survey," Value in Health Regional Issues, vol. 7, pp. 54-66, 2015. http://dx.doi.org/10.1016/j.vhri.2015.07.004.

[5] Yusof, Zamros Y M Jaafar, Nasruddin, "Health promoting schools and children's oral health related quality of life.," Health and quality of life outcomes, vol. 11, 2013. doi: 10.1186/1477-7525-11-205.

[6] B. Pasiga, "The Behavior of Indonesian Society about Access Dental Care, using a Telephone SurveyThe Behavior of Indonesian Society about Access Dental Care, using a Telephone SurveyThe Behavior of Indonesian Society about Access Dental Care, using a Telephone Survey," Journal of
International Dental and Medical Research, vol. 11, no. 2, pp. 663-668, 2018.

[7] Roncalli, Angelo Giuseppe Tsakos, Georgios Sheiham, Aubrey de Souza, Georgia Costa Watt, Richard G, "Social determinants of dental treatment needs in Brazilian adults," BMC Public Health, vol. 14, no. 1, p. 1097, 2014. http://bmcpublichealth.biomedcentral.com/articles/10.1186/ 1471-2458-14-1097.

[8] D. GO Brien, "Emergency Room Utilization for Dental Treatment: the Socioeconomic Impact of Utilizing Emergency Rooms to Treat Non-Traumatic Dental Issues," Online Journal of Dentistry \& Oral Health, vol. 2, no. 5, pp. 2-5, 2020.

http://www.tandfonline.com/doi/full/10.1179/14653120722 5022185.

[9] Chou, Chiu Fang Vallin, Thomas Rogers, Shane Streeter, Robin A. Worede, Isaac Washko, Michelle M. Zangaro, George A. Ungard, Jesse, "Impact of the Health Resources and Services Administration's state oral health workforce grant program on dental workforce density and access to oral health care," Evaluation and Program Planning, vol. 75, pp. 43-53, 2019.

https://doi.org/10.1016/j.evalprogplan.2019.04.004.

[10] Cristina, Sonia Chaves, Lima Maria, Ana Feire, Lima, "Dental service coverage and oral health promotion community actions in primary care in Brazil between 2003 and 2019," Health Policy OPEN, p. 100022, 2020. https://doi.org/10.1016/j.hpopen.2020.100022.

[11] Craig, Maureen H. Scott, Jo Anna M. Slayton, Rebecca L. Walker, Amy L. Chi, Donald L., "Preventive dental care use for children with special health care needs in Washington's Access to Baby and Child Dentistry program," Journal of the American Dental Association, vol. 150, pp. 42-48, 2109. https://doi.org/10.1016/j.adaj.2018.08.026.

[12] Luo, Huabin Wu, Qiang Bell, Ronny A. Wright, Wanda G. Garcia, Raul I. Quandt, Sara A., "Trends in use of dental care provider types and services in the United States in 20002016: Rural-urban comparisons," Journal of the American Dental Association, vol. 151, no. 8, pp. 596-606, 2020. https://doi.org/10.1016/j.adaj.2020.04.026.

[13] A. Vesna, "Oral Health and Public Health Systems in Europe," Online Journal of Dentistry \& Oral Health, vol. 1, no. 3, p. 33552, 2018. doi: 0.33552/ojdoh.2018.01.000514.

[14] Who, Oral Health Surveys - Basic Methofd, WHO, 2013.

[15] Musskopf, Marta Liliana Milanesi, Fernanda Carpes Rocha, José Mariano da Fiorini, Tiago Moreira, Carlos Heitor Cunha Susin, Cristiano Rösing, Cassiano Kuchenbecker Weidlich, Patricia Oppermann, Rui Vicente, "Oral health related quality of life among pregnant women: a randomized controlled trial," Brazilian Oral Research, vol. 32, pp. 1-10, 2018. doi: 10.1590/1807-3107bor-2018.vol32.0002.

[16] Paula, Janice S Leite, Isabel CG Almeida, Anderson B Ambrosano, Glaucia MB Pereira, Antonio C Mialhe, Fabio $\mathrm{L}$, "The influence of oral health conditions, socioeconomic status and home environment factors on schoolchildren's selfperception of quality of life," Health and Quality of Life Outcomes, vol. 10, no. 1, p. 6, 2012. http://hqlo.biomedcentral.com/articles/10.1186/1477-752510-6.

[17] Schluter, Philip J. Askew, Deborah A. McKelvey, Victoria A. Jamieson, Hamish A. Lee, Martin, "Oral Health Among Older Adults With Complex Needs Living in the Community and in Aged Residential Care Facilities within New Zealand," Journal of the American Medical Directors Association, pp. 1-8, 2020. https://doi.org/10.1016/j.jamda.2020.06.041.

[18] Huang, Jing Yang Yu, Hui Chieh Chen, Yi Tzu Chiu, Yu Wei Huang, Shang Ming Chang, Yu Chao, "Analysis of 
emergency dental revisits in Taiwan (1999-2012) from Taiwanese National Health Insurance Research Database (NHIRD)," Journal of Dental Sciences, vol. 14, no. 4, pp. 395-400, 2019. https://doi.org/10.1016/j.jds.2019.08.003.

[19] Si, Yan Tai, Baojun Hu, Deyu Lin, Huancai Wang, Bo Wang, Chunxiao Zheng, Shuguo Liu, Xuenan Rong, Wensheng Wang, Weijian Feng, Xiping Wang, Xing, "Oral health status of Chinese residents and suggestions for prevention and treatment strategies," Global Health Journal, vol. 3, no. 2, pp. 50-54, 2019. https://doi.org/10.1016/j.glohj.2019.06.004.

[20] Pasiga, B; Akbar,FH, "The Impact of Dental Caries Severity on the Quality of Life of Children Aged 8-10 Years Using Child's Perception Questionnaire (CPQ 8-10) in North Mamuju, Indonesia," Merit Research Journal of Medicine and Medical Sciences, vol. 6, no. 11, pp. 379-386,, 2018.

[21] McGrath, Colman Bedi, Raman, "Dental services and perceived oral health: Are patients better off going private?,"
Journal of Dentistry, vol. 31, no. 1, pp. 217-221, 2003. https://doi.org/10.1016/j.adaj.2018.08.026.

[22] Kuchta, Ewa Chałas, Renata Szalewski, Leszek PietrykaMichałowska, Elżbieta Szymańska, Jolanta, "Dental treatment needs in patients of a Lublin dental clinic aged 3554," Polish Journal of Public Health, vol. 126, no. 3, pp. 138141, 2017. doi: 10.1515/pjph-2016-0029.

[23] Kamińska, Aneta Szalewski, Leszek Batkowska, Justyna Wallner, Jan Wallner, Eliza Szabelska, Anna Borowicz, Janusz, "The dependence of dental caries on oral hygiene habits in preschool children from urban and rural areas in Poland," The dependence of dental caries on oral hygiene habits in preschool children from urban and rural areas in Poland , vol. 23, no. 4, pp. 660-665, 2016. $0.5604 / 12321966.1226863$. 